\title{
To roll the eyes and snap a bite - function, development and evolution of craniofacial muscles
}

\author{
Frank R. Schubert ${ }^{a}$, Arun J. Singh ${ }^{\text {b }}$, Oluwatomisin Afoyalan ${ }^{a}$, Chrissa Kioussib and Susanne Dietrich*a \\ a Institute of Biomedical and Biomolecular Sciences, University of Portsmouth, Portsmouth, UK \\ ${ }^{\mathrm{b}}$ Department of Pharmaceutical Sciences, College of Pharmacy, Oregon State University, Corvallis, OR \\ 97331, USA
}

* Corresponding author: susanne.dietrich@port.ac.uk

\begin{abstract}
Craniofacial muscles, muscles that move the eyes, control facial expression and allow food uptake and speech, have long been regarded as a variation on the general body muscle scheme. However, evidence has accumulated that the function of head muscles, their developmental anatomy and the underlying regulatory cascades are distinct. This article reviews the key aspects of craniofacial muscle and muscle stem cell formation and discusses how this differs from the trunk programme of myogenesis; we show novel RNAseq data to support this notion. We also trace the origin of head muscle in the chordate ancestors of vertebrates and discuss links with smooth-type muscle in the primitive chordate pharynx. We look out as to how the special properties of head muscle precursor and stem cells, in particular their competence to contribute to the heart, could be exploited in regenerative medicine.
\end{abstract}

Key words: vertebrate head and neck muscle; eye muscle; jaw muscle; facial muscle; pharyngeal muscle; paraxial head mesoderm; secondary heart field; somites; Cyp26C1; Pitx2; Tbx1; MyoR/Musculin; Capsulin; MyoD; Pax7; RNAseq; chordate ancestors; cephalisation; muscular dystrophies; cardiovascular disease; stem-cell therapy.

\section{Introduction}

The ability to move is one of the criteria for life. In complex, multicellular (metazoan) animals, movement relies on a specialised, contractile tissue - muscle. Three types of muscle are recognised: smooth muscle that controls the dilation and contraction of internal organs, cardiac muscle responsible of pumping blood, and skeletal muscle that allows locomotion (reviewed in [1]). In all types of muscle tissues, contractility relies on the calcium- and ATP-dependent sliding of myosin versus actin protein filaments, accompanied by additional proteins. However, in the three different muscle types, distinct myosins and actins are used. In heart and skeletal muscle, the contractile protein filaments are organised into reiterated units termed sarcomeres, which under a light microscope are recognisable as cross-striations. Contraction may be initiated by motor neurones, pacemaker cells, hormones and other chemical signals. However, only skeletal muscle is innervated by motor neurones that are linked to the central nervous system as higher regulatory unit. Thus, only skeletal muscle is under voluntary control. 
In vertebrates, all skeletal muscle uses cholinergic neurones to initiate contraction [1]. All skeletal muscle consists of elongated, syncytial muscle fibres that arise via fusion of individual muscle cells. When skeletal muscle cells first develop, basic helix-loop-helix transcription factors of the MyoD family, also known as muscle regulatory factors (MRF), cooperate with Mef2 and Six transcription factors to activate the genes required for muscle structure and function, to exit cell cycle and to achieve stable, terminal differentiation (reviewed in [2, 3]). Skeletal muscle may undertake fast contractions fuelled by cytoplasmic glycolysis, or more sustained contractions powered by mitochondrial oxidative phosphorylation [1]. Yet, a given anatomical muscle may contain fast as well as slow-twitch fibres or may switch fibre type for example during metamorphosis [4]. Thus, vertebrate skeletal muscle, irrespective of its precise location, function or ontogeny, is considered a variation of the same skeletal muscle theme.

In the trunk, almost all skeletal muscle serves the function of locomotion, allowing powerful swimming movements of vertebrate fishes in water or limb-based locomotion of tetrapods on land and in the air. Yet all vertebrates have craniofacial skeletal muscles that do not serve in locomotion. Instead, these muscles have many diverse roles from controlling eye movements to, in humans, speech (reviewed in [5]). Muscles for locomotion exclusively develop from the segmented paraxial mesoderm known as somites. Some of the head muscles also develop from somites, namely the rostral-most occipital somites. These somites have been secondarily incorporated into the head [6]. For other head muscles, no ancestor linked to locomotion has ever been found, and thus, they can be considered genuine head muscles.

In the last 20 years, evidence accumulated that genuine head and body muscles are distinct. Head muscles arise form a specialised tissue, the unsegmented paraxial head mesoderm (phm), with some contribution of the pre-chordal mesoderm and possibly the lateral mesoderm [7-13]. Studies first performed in the chicken $[14,15]$ and then reiterated in other model organisms (reviewed in [16]) revealed that head muscles use a distinct programme to initiate myogenic differentiation, and they generate satellite cells, muscle-specific stem cells for postnatal muscle formation and repair, in a specialised way [17]. Moreover, head and trunk muscle seem to be differentially targeted or spared by specific muscular dystrophies, diseases that lead to the weakening or degeneration of skeletal muscle; specifically eye muscles are exempt from muscular dystrophies affecting the body musculature [18].

This article will review the head programme for head muscle development and muscle stem cell development, and provide novel molecular data on the properties of the paraxial head mesoderm. We will discuss the origin of head muscle in the chordate ancestors of vertebrates, and we will look out at how our growing understanding of head muscle development could inform approaches in regenerative medicine.

\section{Diverse roles of vertebrate head muscles, but two original functions}

In to-date's jawed vertebrates, head muscles serve many diverse purposes. However, these muscles can be grouped according to their developmental origin, their connective tissue, and their innervation (Fig.1). The most stereotype use of vertebrate head muscles is that of the six eye (extraocular) muscles (eom), innervated by the oculomotor, trochlear and abducens nerve (cranial nerve III, IV, VI), respectively, that rotate the eye ball and hence, aid vision (reviewed in [5]). In animals with a nictitating membrane, the lateral rectus splits to also supply the retractor bulbi muscle that pulls the eye ball deeper into the skull; in mammals, further accessory eye muscles to close the eye lids evolved. However, the muscles with a primary function in eye movement are conserved between jawed and 
jawless vertebrates. The eom express multiple myosin isoforms including embryonic and cardiac myosins, and they contain poly-innervated fibres with en grappe motor endplates in addition to the singly innervated fibres with en plaque end plates found throughout all skeletal muscle. This arrangement allows fast as well as tonic contraction [19-21]. Interestingly, mammalian eom are accompanied by special, constantly active muscle stem cells, that help to continuously remodel the muscle [22, 23], and this may account for the sparing of eom for example in Duchenne Muscular Dystrophy. In the zebrafish however, eom repair seems to be facilitated by Fgf-driven muscle cell dedifferentiation and re-entry of the cells into cell cycle [24, 25].

Different to the eye muscles, the other head muscles have multiple roles in food uptake and swallowing, the protection of the sensory organs, the generation of sound and the movement of the face $[5,26]$. They can be grouped according to their primary role and innervation patterns. Muscles that connect the skull vault and the lower jaw typically close the jaws. They are innervated by the mandibular branch of the trigeminal nerve (cranial nerve $\mathrm{V}$ ). Interestingly, a number of predatory vertebrates express a "superfast" masticatory myosin heavy chain (MyHC) in their jaw muscles that allows to snap the jaws shut. Phylogenetic and immunohistochemical analyses suggested that this masticatory $\mathrm{MyHC}$ evolved in early gnathostomes, but its use was abandoned when animals adapted to vegetarian diets [27]. Muscles that link the lower jaw with the hyoid bone pull the jaws caudally, thus opening the jaws. They are innervated by the facial nerve (cranial nerve VII). The facial nerve also innervates superficial muscles that link the skull and the skin, or run in the skin only. Their primary role is to control the cranial openings, but in mammals they have an additional role in facilitating facial expression. Pharyngeal muscles that shorten and widen the pharynx, and laryngeal muscles that control the entry into the air sacs/lungs in lung-breathing vertebrates, are innervated by the glossopharyngeal and vagal nerves (cranial nerves IX and X). In humans, the intrinsic laryngeal muscles work the voice cords, thus generating sound. In birds, sound is generated in the syrinx where the trachea forks and connects to the lungs; this allows two sounds to be generated simultaneously. In jawed vertebrates, the opening of jaws is assisted by a set of infra-hyoid (caudal external laryngeal) muscles that originate further caudally; they are not innervated by cranial nerves but by the most rostral spinal nerves and aid the suppression of the hyoid apparatus. Moreover, food uptake and mastication is supported by hypoglossal/hypopharyngeal muscles that include the tongue muscles; they are innervated by the hypoglossal nerve (cranial nerve XII) which is thought to represent a modified spinal nerve [28].

In the body, somatic motor neurones, i.e. neurones that innervate trunk skeletal muscle, have cell bodies located ventrally in the somatic motor column of the spinal cord, express the Lim homeodomain protein IsI 2 and send their axons out via a ventral exit point [29]. Spinal cord visceral motor neurons also have ventrally exiting axons, but their cell bodies are located dorsal to the somatic motor column. Moreover, they do not express Is|2. Importantly, they synapse onto neurons located in ganglia of the autonomic (sympathetic and parasympathetic) nervous system and hence control their targets, namely cardiac muscle and smooth muscles of the viscera, only indirectly. In the head, eom are supplied by Is 2 expressing somatic motor neurons. Yet while both oculomotor (cranial nerve III) and abducens neurons (cranial nerve VI) send their axons towards a ventral exit point; the trochlear axons (cranial nerve IV) decussate and exit dorsally, possibly a consequence of having to cross the midline to innervate their target muscle on the opposite side of the head (Fig.1C). In stark contrast to eom-innervating cranial nerves, cranial nerves controlling the various muscles for food uptake and the workings of the pharynx and larynx lack Is 2 expression, and their cell bodies are located dorsal to the somatic motor column [29]; reviewed in [30]. Thus, they share properties with general visceral motor neurones. However, their axons exit the neural tube via a dorsal exit point and, importantly, they directly synapse with muscle. Thus, these nerves are referred to as pharyngeal, branchial or special 
visceral motor neurones (Fig.1D). Taken together, based on their general function and innervation pattern, head muscles can be grouped as eom and as, in the wider sense, pharynx/cranial openingsassociated muscles; they are assisted by infra-hyoid and tongue muscles which can be classified as trunk muscles.

Despite their shared, curious innervation by special visceral neurones, pharyngeal muscles seem very divers and complex. Yet, comparative anatomical studies and fossil finds allowed to trace them back to a more simple arrangement: Jawed vertebrates evolved from aquatic ancestors that probably resembled the lampreys and hagfish still alive to date [31,32]. These animals do not have jaws. Instead, they have suckers with which they attach themselves to their food source, decaying fish for example, and they rasp rather than bite off pieces of food. Jawless vertebrates, in turn, evolved from invertebrate chordates. Sequence analyses suggest that the closest living relatives of vertebrates are urochordates (tunicates), followed by cephalochordates (lancelets) and ambulacrarians (hemichordates and echinoderms), respectively [33]. Most tunicates have adapted to a sessile life style, secondarily reduced many body structures and lost regulatory genes such as those for retinoic acid controlled rostrocaudal patterning [34]. Hemichordates on the other hand have a body plan that lacks a number of chordate features [5]. Hence, of the extant relatives of vertebrates, lancelets might, in anatomical terms, show most of the features that were present when vertebrates first evolved. What unites primitive vertebrates, invertebrate chordates and hemichordates is the presence of a perforated pharynx set up for filter-feeding. This pharyngeal basket initially consisted of an ectodermal and endodermal component, with cilia moving the water and food particles along [35]. The presence of mesoderm-derived muscle along the pharynx in lancelets together with evidence for predatory behaviour in lancelet larvae suggests that already invertebrate chordates evolved a more active control over their food uptake [36, 37]. As vertebrates emerged, they acquired the ability to also extract oxygen from the water passing through the pharyngeal slits, thus bestowing the pharynx with a respiratory function. Moreover, they evolved neural crest cell derived endoskeletal cartilage elements that strengthened the pharyngeal arches, thereby allowing an increase in water flow and gill ventilation (for evidence of transient cellular cartilage in in larval lancelets see [38]). These reiterated units of tissue, each consisting of cartilage elements, muscle, a central blood vessel (aortic arch) and a cognate cranial nerve, and separating the pharyngeal openings, are known as pharyngeal or, with reference to their respiratory role, branchial or gill arches. They still develop in all vertebrates, no matter whether or not the animal will eventually use air sacs or lungs (reviewed in [39, 40]). During the evolution of jawed vertebrates, the first of these pharyngeal arches changed into jaws, with the associated muscles specialising in jaw closure. The subsequent pharyngeal arches became a jaw support system, with specifically the $2^{\text {nd }}$ pharyngeal arch delivering the muscle to open the jaws, as well as controlling the other cranial openings. Their evolutionary origin however unites all these muscles as muscles associated with the reiterated pharyngeal (branchial) arches, hence the commonly used term "pharyngeal arch muscles" (pam) or "branchiomeric muscles".

\section{Developmental anatomy of vertebrate head and trunk muscles}

In vertebrates and cephalochordates, muscle for locomotion is derived from reiterated blocks of paraxial mesoderm termed somites; in urochordates reiterated cell groups are absent as the animals have secondarily lost somites ([41] and references therein). Somites are located on either side of the axial mesoderm, the notochord, and the neural tube. In vertebrates, somites form at regular intervals in a rostral to caudal direction. This process is controlled by a molecular clock, driven by regular NotchDelta signalling, and a caudal=high-rostral=low Fgf gradient that allows cells to group and mature 
together when Fgf levels have fallen below a threshold [39, 42]. In lancelets, only the caudal somites are generated consecutively, whereas the rostral somites bud off the primitive endoderm. Yet the separation of the somite from the developing gut is also controlled by Notch-Delta signalling [43, 44]. In lancelets, but also primitive vertebrates, most of the somite quickly differentiates into functional skeletal muscle blocks, termed myotomes; in vertebrates, the somites also deliver the vertebral column and ribs ([45, 46]; reviewed in [47]). As contractile muscle fibres are orientated in a rostrocaudal direction, they facilitate side-to-side undulations, which was the main movement pattern before paired fins/ limbs emerged. During the evolution of jawed vertebrates, three major innovations allowed the diversification of movement patterns: Firstly, myotomes became dorsoventrally subdivided and separately innervated, thus allowing upwards/downwards movements as well as sideto-side undulations; this provided three-dimensional mobility (reviewed in [48]; [49]). Secondly, the ventrolateral aspect of the myotomes acquired the ability to grow deep into the lateral mesoderm, thereby fully muscularising the body wall [50]. Thirdly, myogenic cells at the dorsomedial and ventrolateral extremes of the somites acquired the ability to withhold differentiation and detach from the somite. They eventually also acquired the ability to undertake active, long-range migration, thereby providing the muscles of the osteichthyan paired fins/limbs, their hypopharyngeal/ hypoglossal muscles, where present, their cloacal muscles, and in mammals, the diaphragm muscles ([51]; reviewed in [52]. Within the fins/limbs, the cells regroup, following the instructions provided by the fin/limb connective tissue [53]. This ability to depart from the strict segmental pattern and to become organised into complex muscle groups is thought to be a major reason for the eventual evolution of tetrapod load-bearing limbs.

Lineage tracing experiments showed that the eom and the muscles of the three most rostral pharyngeal arches develop from the non-somitic paraxial head mesoderm (phm, Fig.1A, orange and pink shading), with a contribution from the axially located pre-chordal plate [7-11]. The phm is sizeable and reaches from the rostral end of the embryo to the level of the otic vesicle. Since development proceeds in a rostrocaudal direction, the phm is established before the first somite emerges. The phm is laid down as a loosely organised mesenchyme. Originally thought to show a cryptic metamerism, this idea has now been dismissed [54]. Moreover, genes that are crucial for the generation of somitic metamerism are not expressed in the phm [55]. Thus, many authors favour the idea that the phm is a novel, vertebrate-specific tissue (reviewed in [16]).

In some vertebrates, late in development eventually mesodermal vesicular structures known as head cavities appear, which were once thought to resemble somites [56]. Moreover, the withdrawal of Fgf signalling readily abolishes the formation of rostral somites in the cephalochordate Amphioxus [57, 58]. Thus, as an alternative idea it was proposed that the vertebrate phm secondarily lost its segmental organisation akin to the experimental loss of rostral somites in the lancelet, and that head cavities are the remnants of head somites [59]. Head cavities do not show a somitic organisation with a basal lamina on the outside [60]. Moreover, their relevance for the formation of genuine head muscles is unclear. Thus, to which extent vertebrates lost the original segmentation of the rostral-most somites or indeed evolved a new tissue rostral to the series of somites remains controversial (see: [61, 62]).

Lineage tracing experiments focusing on the somites have shown that the rostral-most, anatomically defined somites, the occipital somites, deliver the hypopharyngeal/ tongue muscles. Together with the more caudally located cervical somites, they also deliver the muscles associated with the neck vertebral column [7, 10,11] (Fig.1A, green shading). The hypopharyngeal muscle precursors do not enter the pharyngeal arches but take a route around the pharyngeal arches, eventually following the floor of the pharynx in a rostral direction ([63] and references therein). Notably, the occipital somites develop distinguishable myotomes that segregate into epaxial and hypaxial components [7, 10, 11]. 
Thus, despite being having been incorporated into the head, occipital somites retained the majority of their original "trunk" features.

Currently, the origin of muscles that develop in the caudal pharyngeal arches and that link the head and the shoulder girdle is controversial. Lineage tracing experiments using tissue grafting in the chicken suggested a somitic origin [7-11]. Using genetic lineage tracing in the mouse, it emerged that in mammals, phm-derived cells providing pharynx-associated striated muscle migrate caudally to give rise to voluntary oesophageal muscles required for active swallowing [64]. Notably, a recent reevaluation the origin of the cucullaris muscle (trapezius and sternocleidomastoideus in mammals) traced this muscle to the occipital lateral mesoderm [12], and genetic lineage tracing and the tracing of gene expression histories in the mouse suggested that there is a clonal relationship between precursors for this muscle and cells contributing to the heart $([12,13]$, Fig.1A, pink-lilac stripes, and see section 4.3). Thus, these studies proposed the cranial and occipital lateral mesoderm as further source of head and neck skeletal muscle. The neck as an anatomically defined region of the vertebral column is a tetrapod innovation [32]. It emerged during the transition to full, ribcage-assisted lung breathing. During this process, the shoulder girdle lost its original role, namely forming the rear wall of the gill chamber; it re-located to a more caudal position, thereby stretching out and repurposing the muscles that originally served the shoulder girdle's respiratory function. Moreover, with the transition to lung breathing, the number of pharyngeal arches, originally extending caudally beyond the phm-somite boundary, was reduced. Yet the ability of non-somitic mesoderm to generate skeletal muscle may have prevailed. Taken together, amniotes present a derived condition, and possibly, fate mapping of somites, phm and lateral mesoderm in anamnia will be required to clarify the issue.

While the developmental source of vertebrate head muscles can be traced back to two, possibly three sources, the phm, the occipital somites and the head and occipital lateral mesoderm, it is remarkable that all connective tissue in the head is derived from neural crest cells, whereas in the trunk, connective tissue is mesoderm-derived [7, 10,11] (Fig.1B). We showed that head muscles, like trunk muscles, initially develop independent of their cognate connective tissue [65]. However, eventually the tissues become interdependent [66]. Thus, somites recruited into the head during vertebrate evolution must have acquired the ability to "read" signals from the neural crest derived connective tissue. However, molecular studies showed that the programmes for head and trunk connective tissues converged, with the transcription factor Scleraxis controlling tendon formation in both [66]. Thus, the adjustment somitic cells had to make may have been smaller than previously anticipated.

\section{The molecular control of head and trunk myogenesis - evidence for a discrete head programme}

\subsection{The somitic/trunk programme}

The vast majority of vertebrates and invertebrate chordates develop via motile juvenile (larval) forms [5]. Thus functional muscle for locomotion, i.e. the formation of trunk myotomes, is required quickly. This is achieved via a regulatory cascade whereby the basic-helix loop-helix transcription factor MyoD, in collaboration with Mef2 and Six transcription factors, activates genes that encode for muscle structural and functional proteins, including the key components of the sarcomere and the neuromuscular junction (reviewed in [67, 68]). As with most specialised cells, terminal differentiation and cell division are incompatible - for example cell cycle promoting cyclin dependent kinases (Cdk) inactivate MyoD $[69,70]$. Thus, while MyoD levels build up, myogenic cells may still divide a number of times (as transit amplifying cells). However, eventually MyoD levels are high enough to trigger the expression of cell cycle inhibitors and genes for terminal differentiation (reviewed in [3, 70, 71]). 
The process of myogenesis removes the cells from the precursor pool and limits muscle growth and repair. Yet, already in chordates such as the lancelet, cells are being set aside in development that are myogenic but held in an undifferentiated state $[72,73]$. These cells can asymmetrically divide to produce a new undifferentiated cell and a cell committed to differentiation, and thus qualify as stem cells. Cell ablation studies revealed that muscle stem cells account for the vast expansion of muscle in juveniles and young adults; in teleosts, muscle grows indefinitely via this mechanism ([74];reviewed in [2, 3]; in amniotes, adult muscle mainly expands via hypertrophy). Moreover, muscle stem cells are required for adult muscle homeostasis and repair. In vertebrates, muscle stem cells univocally express the paired and homeobox transcription factor Pax7, while in the lancelet, a highly related pax $3 / 7$ gene is expressed [2, 3, 73, 75]. Notably, in the vertebrate trunk, Pax3 and Pax7 expressing muscle stem cells are deployed early, held in a specialised compartment of the somite, the dermomyotome, which serves as external cell source already for embryonic muscle expansion [76-78].

During the evolution of jawed vertebrates, the genome was duplicated twice, followed by a further round of genome duplication in teleost fish $[79,80]$. Not all duplicates were retained, and frequently, the retained genes underwent sub- or neo-functionalisation. Thus, where there was a single chordate pax3/7 gene, there are distinct $\mathrm{Pax} 3$ and $\mathrm{Pax} 7$ genes in gnathostomes, where there was a single chordate myod gene (two independently duplicated genes in amphioxus, $[45,46]$ ), there are Myf5, MyoD, MyoG and Mrf4 in jawed vertebrates [81-83]. In jawed vertebrates, Pax3 has overlapping roles with Pax7 in the initial establishment of muscle stem cells in the embryo [2, 84]; whereas Mrf genes typically operate in the sequence Myf5-Myod-Myog, with Myf5 committing cells to a myogenic fate, MyoD setting cells up for differentiation and MyoG initiating terminal differentiation $([17,85]$; reviewed in [2, 3, 71]). Importantly, in Pax3/Pax7 expressing muscle progenitor and muscle stem cells, these factors are required for the initiation of myogenesis, binding to the Myf5 as well as the MyoD promoters [84, 86-90]. Moreover, in amniotes, Pax3 and Pax7 have acquired new roles in somite epithelialisation, and the entire somite expresses $\mathrm{Pax} 3$ and $\mathrm{Pax} 7$ before expression becomes restricted to the dermomyotome [91]. Thus, most of the trunk muscle regulatory network begins with Pax3/7 upstream of Mrf genes.

\subsection{The phm/head programme}

Gene expression and functional studies of more than 20 years established that vertebrate head muscle formation also employs Mrf, Mef2 and possibly Six genes (reviewed in [16]. However, compared to somitic myogenesis, head muscle formation is severely delayed ([92], Fig,2). When phm was transplanted into a trunk environment, the tissue failed to read muscle inducing signals and hence, failed to differentiate into muscle [15]. Yet when somites were grafted into the head, they were able to differentiate $[14,93]$. These effects were attributed to Wnt signalling molecules which are crucial for the induction of somitic myogenesis but suppress myogenesis from the phm, and long-lasting cranial Fgf signalling that keeps cells undifferentiated [65, 94].

Notably, in the phm neither Pax3 nor Pax7 are expressed prior to the onset of myogenesis; in fact, Pax3 is not expressed at all and Pax7 expression occurs after the onset of Mrf expression and myogenesis [14, 15, 17, 55]; Fig.2). Moreover, Pax7 expression occurs in cells that previously expressed MyoD [17]. In cells not yet committed to myogenesis, MyoD activates the genes in the trunk associated with the muscle precursor/ muscle stem cell state including Pax7 [95]. This suggests that, in contrast to the trunk, in the head mesoderm Mrf are upstream of Pax7 and control the formation of Pax7-positive head muscle stem cells. 
The absence of upstream regulators of somitic myogenesis in the head prompted a search for genes that may initiate genuine head myogenesis. Several candidates emerged, and they showed a highly dynamic expression pattern as a result of interdigitating retinoic acid signalling, Fgf signalling and Bmp signalling ([55, 96, 97]; Fig.3): In gnathostomes, the inhibitor of retinoic acid signalling, Cyp26C1, is expressed as soon as the phm is established underneath the prospective fore-, mid- and rostral hindbrain. It is followed by the expression of the paired-like homeodomain transcription Pitx2 in the rostral phm and the T-box transcription factor Tbx1 in the caudal phm. Within the confinement of the Pitx2 domain, expression of the paired-like homeodomain transcription factor Alx4 and that of the basic-helix-loop-helix transcription factor Musculin (=Msc, MyoR) emerges. Thereafter, in response to enhanced Fgf levels and fading retinoic acid levels, the expression domain of Msc expands caudally and that of Tbx1 expands rostrally. As a consequence, the rostral phm surrounding the eye expresses Pitx2 and Msc, the phm of the $1^{\text {st }}$ pharyngeal arch expresses Pitx2, Msc as well as Tbx1, the phm of the remaining pharyngeal arches expresses Msc and Tbx1 [97]; Fig.2A).

Functional studies on Cyp26C1 were somewhat inconclusive, possibly owing to functional redundancy with other retinoic acid inhibitors [98, 99]. Misexpression studies for the transcription factors Pitx2, Msc and Tbx1 showed that they delay differentiation, partly by maintaining active cell proliferation [100]. Knock out experiments however established that the genes are needed for eye muscle, jaw muscle and caudal branchiomeric muscle formation, in line with their respective overlapping expression domains. Specifically, Pitx 2 is required for the survival of the periocular cells from which eom develop; it directly activates the Myf5 and MyoD promoters and thus ensures eom differentiation $[101,102]$. In addition to this, Pitx2 also controls the establishment of the eom specific myosin profile and the en grappe motor endplates [19]. In the first arch, Pitx2 is required for the expression of Tbx1, Tcf21/Capsulin, and Msc [103]; moreover, Pitx2 operates a positive feedback mechanism with Fgf [104]. Msc mutants alone show little of a phenotype, but when the highly related Tcf21 (=Capsulin) gene is inactivated, too, mandibular arch phm is lost and muscle development fails [105]; the mesoderm of the other arches is probably rescued by Tbx1. Notably, also Msc can activate Mrf genes [106]. Tbx1 roles are complex as the gene is active both in the endoderm and mesoderm [107, 108]. In the pam, cell-autonomous activity is required [108, 109], operating in a feedback loop with Fgf and Pitx2 [110] and genetically interacting with Lhx2 [111]. Notably, also Tbx1 is genetically and molecularly upstream of Mrf $[112,113]$. Thus, in the head programme of muscle development, the transcription factors demarcating the early head mesoderm take the place of Pax3/7 in establishing myogenic competence. Yet once myogenesis is initiated, the head and trunk programmes converge (Fig.4).

Given that the entry into muscle differentiation seems to be so different between the genuine trunk and head paraxial mesoderm, we were interested in understanding how fundamental these differences might be. We therefore carried out an RNAseq analysis, comparing the transcriptome of the phm and not yet segmented paraxial trunk mesoderm (segmental plate, sp) of 1 day old, 1-6 somite stage chicken embryos. The analysis revealed remarkable differences in the expression profiles between the two tissues, with well over 1000 genes differentially expressed (unpublished observations; Fig.5). Interestingly, the GO term 'muscle organ development' was highly enriched in both tissues, but with an emphasis on cell adhesion and extracellular matrix molecules in the phm and genes conferring trunk axial identities, including Hox genes, in the $\mathrm{sp}$. In the sp, genes associated with 'segment specification' highly feature, in line with the prospective segmental organisation of the trunk paraxial mesoderm versus the non-segmented phm. Likewise, in the sp genes linked with 'skeletal system development' are enriched, indicating that the $\mathrm{sp}$ is set up to not only deliver muscle but to also make a major contribution to the skeleton (vertebral column), whereas the phm makes a small 
contribution to the base of the skull only $[7,10,11]$. Thus, during early development, the trunk and head mesoderm are very distinct.

\subsection{The link of the phm and heart programme}

Our RNAseq analysis revealed that in the phm, 'heart development' genes feature prominently (Fig.5). Indeed, in situ hybridisation experiments indicate that the expression of phm genes and of genes indicating cardiac differentiation overlaps ([55] and Fig.3). Moreover, the phm but not the trunk mesoderm plays a crucial role in heart development: initial lineage tracing experiments suggested that the vertebrate heart, one of the first organs to be functional in the embryo, originates from the cranial lateral mesoderm (reviewed in [47]). However, similar to skeletal muscle, the primitive heart is insufficient for the adult, and additional cells are needed to provide the in- and outflow tract and all of the epicardium including the coronary arteries. Moreover, refined fate mapping experiments revealed that in all vertebrates cells are secondarily added to the primitive heart ([114-118]; reviewed in [119]). Thus, to date the cells building the primitive heart are referred to as primary/ $1^{\text {st }}$ heart field cells; cells that are added on after the primitive heart formed are the secondary $/ 2^{\text {nd }}$ heart field cells, with an anterior heart field at the outflow, a posterior heart field at the inflow pole.

The secondary heart field cells originate from the remainder of the lateral head mesoderm that was left outside the primitive heart, with a possible contribution by the occipital lateral mesoderm. Importantly, also the phm contributes to the $2^{\text {nd }}$ heart field, with clonally related cells found in pharyngeal skeletal musculature and the in- and outflow portion of the heart. These cells are therefore referred to as cardio-pharyngeal mesoderm ([114-118]; reviewed in [119]). During normal development, only a subset of phm cells will end up in the heart. However, when exposed to the cardiac inducer Bmp2/4, the entire phm responds quickly with the expression of cardiac genes [97]. Moreover, this cardiac competence may be retained for a prolonged period of time [120]. This suggests that cardiac competence is a key feature of the phm.

A myocardial tube ventral to the gut canal and involved in moving blood in a peristaltic fashion is recognised in lancelets, but they do not form a chambered heart [121]. However, a chambered heart is present in ascidians (a subgroup of urochordates/tunicates) and in all vertebrate clades (reviewed in [122]). Genetic studies in vertebrate model organisms showed that the defects in the upstream regulators of head muscle development, specifically defects in Pitx2 and Tbx1, cause cardiac defects [123-127]. Notably, a $2^{\text {nd }}$ heart field not only exists in vertebrates, but also in ascidians, and a role in particular of Tbx1 is evolutionarily conserved $[128,129]$. Thus, a role of $\mathrm{phm} / 2^{\text {nd }}$ heart field genes predates the emergence of vertebrates.

\section{Vertebrate head muscle - a result of chordate cephalisation}

Elaborate head muscles associated with feeding and, in the vertebrate lineage, sense organs, are tightly linked with a general evolutionary trend towards cephalisation. Cephalisation, the concentration of sense organs, feeding apparatus and central nervous system at the head end of the animal, is seen in several animal phyla, most notably arthropods and chordates. In chordates, arguably the arrangement found in vertebrates is the most sophisticated.

For the Ediacaran period (ca. 635-542 million years ago) animals are regarded as grazers, feeding on cyanobacterial mats; early bilaterians are unlikely to have been carnivorous. Increasing oxygen levels in the atmosphere eventually allowed more expensive life styles, particularly greater mobility and the advent of predation [130]. It is not clear when exactly bilaterians diverged into the protostome lineage 
eventually leading to arthropods, and the deuterostome lineage leading to chordates and vertebrates, but the major clades of protostomes and deuterostomes are represented in fossils from the Cambrian (541-485.4 million years ago). The last common ancestor for all deuterostomes was likely filter feeding using a pharyngeal basket, as suggested by early Cambrian fossils possibly representing ancestral deuterostomes such as Saccorhytus [131] which had primitive pharyngeal slits. This lifestyle is still found in extant hemichordates, cephalochordates and urochordates and is already indicative of specialised cranial structures. Notably, the chordate Haikouichthys that lived around 525 million years ago had better-defined head structures with associated sense organs than invertebrate chordates have to date [132]. At the time, however, distinct head structures were more prominent in the dominant Cambrian arthropods, likely due to a change in feeding modes in response to major ecological changes.

Given that extant invertebrate chordates show less defined cranial features than relatives present in palaeozoic times, it is difficult to reconstruct the emergence of head muscles and the underlying regulatory cascades. A number of features however are shared between the pharyngeal apparatus of hemichordates, invertebrate chordates and vertebrates and thus, allow conclusions for the original chordate layout: A gene regulatory network involving $t b \times 1 / 10$ is already present in hemichordates; here however it is restricted to the endoderm as a pharyngeal mesoderm has not yet evolved [35]. In the larvae of the lancelet, an extant cephalochordate, the primitive pharyngeal apparatus expresses cypc26, pitx and tbx1/10, with tbx1/10 expression found in the mesoderm as well as the endoderm $[59,133]$. Cyp26 protects the area from retinoic acid which is produced caudally and, via hox 1 , limits the caudal extent of the pharynx [41]. The mesodermal cells develop as ventrolateral extensions from the rostral somites; these somites are distinct as they that pinch off the gut canal whereas more caudal somites form sequentially from the tail bud ([134]; reviewed in [61]). In contrast to vertebrates, the amphioxus pharyngeal mesoderm does not express mrf genes, which are only expressed in the skeletal muscle of the dorsoventrally located somitic myotomes [45, 46]. Instead, the pharyngeal mesoderm expresses smooth muscle actin [135]. Notably, dorsally exiting motor neurons innervating the adult pterygial muscle and possibly the larval pharyngeal muscle have also been described in these animals [136], and special visceral motors neurones akin to those that innervate vertebrate pam exist in ascidians [137]. Finally MyoR/musculin/capsulin homologues are not only expressed in the pam but also in visceral muscle surrounding the midgut, both in vertebrates and in Drosophila, a protostome organism ([138] and references therein). Thus, it is possible that in early chordates specialised visceral muscles evolved, which in vertebrates became linked with the programme for skeletal myogenesis and with the voluntary control system in the central nervous system, thus turning these muscles into skeletal muscle.

\section{Conclusions and outlook: understanding craniofacial muscle for the advance in science and the therapy of disease}

Here we discussed that head skeletal muscles, while not required for locomotion, serve in food uptake, respiration, control over the cranial opening and vision, which are all crucial for survival. Head muscles originate from three sources, the phm, the lateral head and occipital mesoderm, and the occipital somites, with somites having been incorporated into the head secondarily. Specific genes act upstream in establishing the precursors for eye, jaw and further caudal branchiomeric muscles. Notably, these genes also act upstream in the establishment of a cell lineage that is being added on to primitive heart. This secondary heart field lineage is crucial for the formation of the mature heart and for the pericardium. Given that extant invertebrate and vertebrate chordates had their millions of years of evolution, preserving some, but deviating from many of the original features, we may not 
be able to fully reconstruct head muscle evolution. However, with the evidence accumulating that the non-somitic head musculature is distinct, we can now take an unbiased approach, free from prejudices derived from trunk myogenesis, and really unravel how head muscles develop. This will lead to novel insight into regulatory networks, and will provide a better understanding of how vertebrate head muscle and heart formation are linked. Moreover, it hopefully will spark renewed interest into why muscular dystrophies affect head and body muscles differently. But most importantly, we can take an open-minded approach to muscle stem cells and stem cell based therapies.

\subsection{Cells for the therapy of muscle wasting or volumetric muscle loss}

Healthy skeletal muscle self-repairs due to its in-built adult muscle stem cells. Yet these cell are insufficient in muscle diseases such as muscular dystrophies, in muscle wasting associated for example with cancer or ageing, or when muscle is lost due to accidents or combat wounds. Thus, strategies to collect patient's muscle stem cells from muscle biopsies and to manipulate, expand and back-graft these cells are actively researched (reviewed in [139]). The vast majority of body muscle stem cells are quiescent, waiting to be activated upon injury (reviewed in [2, 3]). These cells do not grow well in standard culture, possibly because they prefer to return to mitotic quiescence. Studies on eom muscle stem cells suggested that a subpopulation of these cells is constantly mitotically active, and these cells may protect the muscles from diseases such as Duchenne muscular dystrophy [22, 23]. Notably, head muscle derived stem cells are able to regenerate body muscle [112]. Thus, eom muscle stem cells may be a very useful source of therapeutic cells to re-build muscle.

\subsection{Cells for cardiac repair}

Associated with more sedentary lifestyles, fast foods and ageing, the incidence of heart disease is increasing worldwide. The adult amniote heart has a limited capacity to regenerate, and cells lost during a myocardial infarction are not replaced. Naturally occurring cell types such as cardiac progenitor/ stem cells, bone-marrow derived mesenchymal stem cells and body skeletal muscle stem cells, or cells generated in vitro such as induced pluripotent stem cells obtained from fibroblasts or ethically very controversial - embryonic stem cells obtained from in vitro fertilisation are all being investigated for their ability to differentiate into cardiomyocytes and to repair the damaged heart (reviewed in [140, 141]). Adult skeletal muscle stem cells associated with head (but not body) muscles still express the early phm genes, suggesting that they may have retained some of their earlier properties [112]. Indeed, the cells can be differentiated into cardiomyocytes, suggesting that they have retained the cardiac potency of the phm [142]. Thus, patient's head muscle stem cells could serve as an autologous source of cells to replace cardiomyocytes lost after myocardial infarction or they could be used to deliver paracrine factors that suppress scar formation and promote cardiac self-repair [143].

\subsection{Learning from the embryo}

Here we reviewed that the phm is a remarkable tissue as it delivers genuine head skeletal muscle and its associated adult stem cells, cells for the secondary heart field, and cells to build the base of the skull, all in a short period of time. Moreover, the phm delivers adult skeletal muscle stem cells that retain some of the properties of the embryonic progenitor cells and, at least for eom muscle stem cells, remain mitotically active. Thus, even if the adult head muscle stem cells themselves turn out not to be that useful as therapeutic cells, the unravelling of the properties of early phm will provide knowledge and tools to evoke desirable properties in therapeutic cells. Indeed, work to reprogram cells into secondary heart field cells is under way (e.g. [144]). Notably, when jaw muscle-derived muscle stem cells were grafted into limb muscles, phm markers disappeared and the cells behaved like trunk muscle stem cells [112]. This suggests that the behaviour of head muscle stem cells is a result of endogenous components and the interactions of the stem cells with their niche. Thus, the challenge 
will be to both, better characterise the properties of the phm and to better characterise how the head environment builds a special stem cell niche - there is still a lot to learn from the embryo.

\section{Acknowledgements}

We thank friends and colleagues for many inspiring discussions, especially colleagues at the Institute of Biological and Biomedical Sciences and the European Xenopus Resource Centre at the University of Portsmouth and L. Alvares, B. Brand-Saberi, A-G. Borycki, T. Brand, M. Buckingham, J. Carvajal, P. Currie, C. Emerson, A. Graham, J. Green, S. Hughes, O. Halevy, C. Jagla, G. Kardon, S. Kuratani, R. Kusakabe, R. Krauss, C. Marcelle, M. Meredith-Smith, A. Münsterberg, D. Noden, F. Pituello, O. Pourquie, T. Rando, R. Renkawitz-Pohl, F. Relaix, M. Rudnicki, C. Stern, S. Schiaffino, S. Tajbakhsh, M. Tanaka, S. Tapscott, M. Torres, E. Tzahor. The work was funded by a grant from the University of Portsmouth, UK. CK and AKS were supported by the College of Pharmacy, Oregon State University, USA. 


\section{References}

1. Alberts, B., et al., Molecular Biology of the Cell. 2015, New York \& London: Garland Publishing Inc.

2. Buckingham, M. and F. Relaix, PAX3 and PAX7 as upstream regulators of myogenesis. Semin Cell Dev Biol, 2015. 44: p. 115-25.

3. Bentzinger, C.F., Y.X. Wang, and M.A. Rudnicki, Building muscle: molecular regulation of myogenesis. Cold Spring Harb Perspect Biol, 2012. 4(2).

4. Nasipak, B. and D.B. Kelley, Developing laryngeal muscle of Xenopus laevis as a model system: androgen-driven myogenesis controls fiber type transformation. Dev Neurobiol, 2012. 72(4): p. 664-75.

5. Goodrich, E.S., Studies on the structure and development of vertebrates. 2 ed. 1958, New York: Dover Publications Inc.

6. Gans, C. and R.G. Northcutt, Neural crest and the origin of vertebrates: a new head. Science, 1983. 220: p. 268-274.

7. Noden, D.M., The embryonic origins of avian cephalic and cervical muscles and associated connective tissues. Am J Anat, 1983. 168(3): p. 257-76.

8. Wachtler, F., et al., The extrinsic ocular muscles in birds are derived from the prechordal plate. Naturwissenschaften, 1984. 71(7): p. 379-380.

9. Wachtler, F. and M. Jacob, Origin and development of the cranial skeletal muscles. Bibl Anat, 1986(29): p. 24-46.

10. Couly, G.F., P.M. Coltey, and N.M. Le Douarin, The developmental fate of the cephalic mesoderm in quail-chick chimeras. Development, 1992. 114(1): p. 1-15.

11. Couly, G.F., P.M. Coltey, and N.M. Le Douarin, The triple origin of skull in higher vertebrates: a study in quail-chick chimeras. Development, 1993. 117(2): p. 409-429.

12. Theis, S., et al., The occipital lateral plate mesoderm is a novel source for vertebrate neck musculature. Development, 2010. 137(17): p. 2961-71.

13. Lescroart, F., et al., Clonal analysis reveals a common origin between nonsomite-derived neck muscles and heart myocardium. Proc Natl Acad Sci U S A, 2015. 112(5): p. 1446-51.

14. Hacker, A. and S. Guthrie, A distinct developmental programme for the cranial paraxial mesoderm in the chick embryo. Development, 1998. 125(17): p. 3461-3472.

15. Mootoosamy, R.C. and S. Dietrich, Distinct regulatory cascades for head and trunk myogenesis. Development, 2002. 129(3): p. 573-583.

16. Sambasivan, R., S. Kuratani, and S. Tajbakhsh, An eye on the head: the development and evolution of craniofacial muscles. Development, 2011. 138(12): p. 2401-15.

17. Meireles Nogueira, J., et al., The emergence of Pax7-expressing muscle stem cells during vertebrate head muscle development. Front Aging Neurosci, 2015. 7: p. 62.

18. Emery, A.E., The muscular dystrophies. Lancet, 2002. 359(9307): p. 687-695.

19. Zhou, Y., D. Liu, and H.J. Kaminski, Pitx2 regulates myosin heavy chain isoform expression and multi-innervation in extraocular muscle. J Physiol, 2011. 589(Pt 18): p. 4601-14.

20. Hebert, S.L., M.L. Daniel, and L.K. McLoon, The role of Pitx2 in maintaining the phenotype of myogenic precursor cells in the extraocular muscles. PLoS One, 2013. 8(3): p. e58405.

21. Saera-Vila, A., et al., Myocyte Dedifferentiation Drives Extraocular Muscle Regeneration in Adult Zebrafish. Invest Ophthalmol Vis Sci, 2015. 56(8): p. 4977-93.

22. McLoon, L.K. and J.D. Wirtschafter, Continuous myonuclear addition to single extraocular myofibers in uninjured adult rabbits. Muscle Nerve, 2002. 25(3): p. 348-58.

23. Kallestad, K.M., et al., Sparing of extraocular muscle in aging and muscular dystrophies: a myogenic precursor cell hypothesis. Exp Cell Res, 2011. 317(6): p. 873-85.

24. Saera-Vila, A., P.E. Kish, and A. Kahana, Fgf regulates dedifferentiation during skeletal muscle regeneration in adult zebrafish. Cell Signal, 2016. 28(9): p. 1196-204.

25. Saera-Vila, A., et al., Autophagy regulates cytoplasmic remodeling during cell reprogramming in a zebrafish model of muscle regeneration. Autophagy, 2016. 12(10): p. 1864-1875. 
26. Diogo, R. and V. Abdala, Muscles of Vertebrates. 2010. 500.

27. Qin, H., et al., A distinct subclass of mammalian striated myosins: structure and molecular evolution of "superfast" or masticatory myosin heavy chain. J Mol Evol, 2002. 55(5): p. 544-52.

28. Kuratani, S., et al., Early development of the hypoglossal nerve in the chick embryo as observed by the whole-mount nerve staining method. Am J Anat, 1988. 182(2): p. 155-68.

29. Varela-Echavarria, A., S.L. Pfaff, and S. Guthrie, Differential expression of LIM homeobox genes among motor neuron subpopulations in the developing chick brain stem. Mol Cell Neurosci, 1996. 8(4): p. 242-57.

30. Chandrasekhar, A., Turning heads: development of vertebrate branchiomotor neurons. Dev Dyn, 2004. 229(1): p. 143-61.

31. Jarvik, E., Basic structure and evolution of vertebrates. Vol. 1. 1980, London and New York: Academic Press. 1-591.

32. Clack, J.A., Gaining Ground. The Origin and Evolution of Tetrapods. 2002, Bloomington: Indiana University Press.

33. Delsuc, F., et al., Tunicates and not cephalochordates are the closest living relatives of vertebrates. Nature, 2006. 439(7079): p. 965-968.

34. Berna, L. and F. Alvarez-Valin, Evolutionary genomics of fast evolving tunicates. Genome Biol Evol, 2014. 6(7): p. 1724-38.

35. Gillis, J.A., J.H. Fritzenwanker, and C.J. Lowe, A stem-deuterostome origin of the vertebrate pharyngeal transcriptional network. Proc Biol Sci, 2012. 279(1727): p. 237-46.

36. Yasui, K., et al., Development of oral and branchial muscles in lancelet larvae of Branchiostoma japonicum. J Morphol, 2014. 275(4): p. 465-77.

37. Webb, J.E., On the feeding and behaviour of the larva of Branchiostoma lanceolatum. Marine Biology, 1969. 3(1): p. 58-72.

38. Jandzik, D., et al., Evolution of the new vertebrate head by co-option of an ancient chordate skeletal tissue. Nature, 2015. 518(7540): p. 534-7.

39. Graham, A., et al., What can vertebrates tell us about segmentation? Evodevo, 2014. 5: p. 24.

40. Graham, A. and J. Richardson, Developmental and evolutionary origins of the pharyngeal apparatus. Evodevo, 2012. 3(1): p. 24.

41. Schubert, M., et al., Retinoic acid signaling acts via Hox1 to establish the posterior limit of the pharynx in the chordate amphioxus. Development, 2005. 132(1): p. 61-73.

42. Ozbudak, E.M. and O. Pourquie, The vertebrate segmentation clock: the tip of the iceberg. Curr Opin Genet Dev, 2008. 18(4): p. 317-323.

43. Beaster-Jones, L., et al., Expression of somite segmentation genes in amphioxus: a clock without a wavefront? Dev Genes Evol, 2008. 218(11-12): p. 599-611.

44. Onai, T., et al., On the origin of vertebrate somites. Zoological Lett, 2015. 1: p. 33.

45. Schubert, M., et al., Differential mesodermal expression of two amphioxus MyoD family members (AmphiMRF1 and AmphiMRF2). Gene Expr Patterns, 2003. 3(2): p. 199-202.

46. Urano, A., et al., Expression of muscle-related genes and two MyoD genes during amphioxus notochord development. Evol Dev, 2003. 5(5): p. 447-58.

47. Gilbert, S.F., Developmental Biology. 10th ed. 2013, Sunderland MA: Sinauer Associates Inc.

48. Fetcho, J.R., A review of the organization and evolution of motoneurons innervating the axial musculature of vertebrates. Brain Res, 1987. 434(3): p. 243-280.

49. Ahmed, M.U., et al., Engrailed controls epaxial-hypaxial muscle innervation and the establishment of vertebrate three-dimensional mobility. Dev Biol, 2017. 430(1): p. 90-104.

50. Shearman, R.M. and A.C. Burke, The lateral somitic frontier in ontogeny and phylogeny. J Exp Zool B Mol Dev Evol, 2009. 312(6): p. 603-12.

51. Cole, N.J., et al., Development and evolution of the muscles of the pelvic fin. PLoS Biol, 2011. 9(10): p. e1001168.

52. Wotton, K.R., F.R. Schubert, and S. Dietrich, Hypaxial muscle: controversial classification and controversial data? Results Probl Cell Differ, 2015. 56: p. 25-48. 
53. Kardon, G., B.D. Harfe, and C.J. Tabin, A Tcf4-positive mesodermal population provides a prepattern for vertebrate limb muscle patterning. Dev Cell, 2003. 5(6): p. 937-944.

54. Freund, R., et al., The metameric pattern of the head mesoderm--does it exist? Anat Embryol (Berl), 1996. 193(1): p. 73-80.

55. Bothe, I. and S. Dietrich, The molecular setup of the avian head mesoderm and its implication for craniofacial myogenesis. Dev Dyn, 2006. 235(10): p. 2845 - 2860.

56. Balfour, F.M., The development of elasmobranchial fishes. J Anat Physiol, 1878. 11: p. 405706.

57. Bertrand, S., et al., Amphioxus FGF signaling predicts the acquisition of vertebrate morphological traits. Proc Natl Acad Sci U S A, 2011. 108(22): p. 9160-5.

58. Bertrand, S., et al., Evolution of the Role of RA and FGF Signals in the Control of Somitogenesis in Chordates. PLoS One, 2015. 10(9): p. e0136587.

59. Koop, D., et al., Roles of retinoic acid and Tbx1/10 in pharyngeal segmentation: amphioxus and the ancestral chordate condition. Evodevo, 2014. 5(1): p. 36.

60. Jacob, M., et al., Ontogeny of avian extrinsic ocular muscles. I. A light- and electronmicroscopic study. Cell \& Tissue Research, 1984. 237(3): p. 549-557.

61. Holland, L.Z., N.D. Holland, and E. Gilland, Amphioxus and the evolution of head segmentation. Integr Comp Biol, 2008. 48(5): p. 630-46.

62. Kuratani, S. and T. Schilling, Head segmentation in vertebrates. Integr Comp Biol, 2008. 48(5): p. 604-10.

63. Lours-Calet, $\mathrm{C}$., et al., Evolutionarily conserved morphogenetic movements at the vertebrate head-trunk interface coordinate the transport and assembly of hypopharyngeal structures. Dev Biol, 2014. 390(2): p. 231-246.

64. Gopalakrishnan, S., et al., A Cranial Mesoderm Origin for Esophagus Striated Muscles. Dev Cell, 2015. 34(6): p. 694-704.

65. Tzahor, E., et al., Antagonists of Wnt and BMP signaling promote the formation of vertebrate head muscle. Genes Dev, 2003. 17(24): p. 3087-3099.

66. Grenier, J., et al., Relationship between neural crest cells and cranial mesoderm during head muscle development. PLoS One, 2009. 4(2): p. e4381.

67. Aziz, A., Q.C. Liu, and F.J. Dilworth, Regulating a master regulator: establishing tissue-specific gene expression in skeletal muscle. Epigenetics, 2010. 5(8): p. 691-5.

68. Fong, A.P. and S.J. Tapscott, Skeletal muscle programming and re-programming. Curr Opin Genet Dev, 2013. 23(5): p. 568-73.

69. Wei, Q. and B.M. Paterson, Regulation of MyoD function in the dividing myoblast. FEBS Lett, 2001. 490(3): p. 171-8.

70. Kitzmann, M. and A. Fernandez, Crosstalk between cell cycle regulators and the myogenic factor MyoD in skeletal myoblasts. Cell Mol Life Sci, 2001. 58(4): p. 571-9.

71. Singh, K. and F.J. Dilworth, Differential modulation of cell cycle progression distinguishes members of the myogenic regulatory factor family of transcription factors. FEBS J, 2013. 280(17): p. 3991-4003.

72. Holland, L.Z., et al., AmphiPax3/7, an amphioxus paired box gene: insights into chordate myogenesis, neurogenesis, and the possible evolutionary precursor of definitive vertebrate neural crest. Evol Dev, 1999. 1(3): p. 153-65.

73. Somorjai, I.M., et al., Vertebrate-like regeneration in the invertebrate chordate amphioxus. Proc Natl Acad Sci U S A, 2012. 109(2): p. 517-22.

74. Gurevich, D.B., et al., Asymmetric division of clonal muscle stem cells coordinates muscle regeneration in vivo. Science, 2016. 353(6295): p. aad9969.

75. Seale, P., et al., Pax7 is required for the specification of myogenic satellite cells. Cell, 2000. 102(6): p. 777-786.

76. Gros, J., et al., A common somitic origin for embryonic muscle progenitors and satellite cells. Nature, 2005. 435(7044): p. 954-958. 
77. Schienda, J., et al., Somitic origin of limb muscle satellite and side population cells. Proc Natl Acad Sci U S A, 2006. 103(4): p. 945-950.

78. Relaix, F., et al., A Pax3/Pax7-dependent population of skeletal muscle progenitor cells. Nature, 2005. 435(7044): p. 948-953.

79. Ohno, S., U. Wolf, and N.B. Atkin, Evolution from fish to mammals by gene duplication. Hereditas, 1968. 59(1): p. 169-87.

80. Dehal, P. and J.L. Boore, Two rounds of whole genome duplication in the ancestral vertebrate. PLoS Biol, 2005. 3(10): p. e314.

81. Franke, F.A., et al., Phylogenetic analysis and expression patterns of Pax genes in the onychophoran Euperipatoides rowelli reveal a novel bilaterian Pax subfamily. Evol Dev, 2015. 17(1): p. 3-20.

82. Muller, P., et al., Evolutionary aspects of developmentally regulated helix-loop-helix transcription factors in striated muscle of jellyfish. Dev Biol, 2003. 255(2): p. 216-29.

83. Atchley, W.R. and W.M. Fitch, A natural classification of the basic helix-loop-helix class of transcription factors. Proc Natl Acad Sci U S A, 1997. 94(10): p. 5172-5176.

84. Relaix, F., et al., Pax3 and Pax7 have distinct and overlapping functions in adult muscle progenitor cells. J Cell Biol, 2006. 172(1): p. 91-102.

85. Berti, F., et al., Time course and side-by-side analysis of mesodermal, pre-myogenic, myogenic and differentiated cell markers in the chicken model for skeletal muscle formation. J Anat, 2015. 227(3): p. 361-82.

86. Bajard, L., et al., A novel genetic hierarchy functions during hypaxial myogenesis: Pax3 directly activates Myf5 in muscle progenitor cells in the limb. Genes Dev, 2006. 20(17): p. 2450-2464.

87. Tajbakhsh, S., et al., Redefining the genetic hierarchies controlling skeletal myogenesis: Pax-3 and Myf-5 act upstream of MyoD. Cell, 1997. 89(1): p. 127-38.

88. Relaix, F., et al., Divergent functions of murine Pax3 and Pax7 in limb muscle development. Genes Dev, 2004. 18(9): p. 1088-1105.

89. Collins, C.A., et al., Integrated functions of $\mathrm{Pax} 3$ and $\mathrm{Pax} 7$ in the regulation of proliferation, cell size and myogenic differentiation. PLoS One, 2009. 4(2): p. e4475.

90. von Maltzahn, J., et al., Pax7 is critical for the normal function of satellite cells in adult skeletal muscle. Proc Natl Acad Sci U S A, 2013. 110(41): p. 16474-9.

91. Schubert, F.R., et al., Early mesodermal phenotypes in splotch suggest a role for Pax3 in the formation of epithelial somites. Dev Dyn, 2001. 222(3): p. 506-521.

92. Noden, D.M., et al., Differentiation of avian craniofacial muscles: I. Patterns of early regulatory gene expression and myosin heavy chain synthesis. Dev Dyn, 1999. 216(2): p. 96-112.

93. Noden, D.M., Patterning of avian craniofacial muscles. Developmental Biology, 1986. 116(2): p. 347-356.

94. von Scheven, G., et al., Neural tube derived signals and Fgf8 act antagonistically to specify eye versus mandibular arch muscles. Development, 2006. 133(14): p. 2731-2745.

95. Gianakopoulos, P.J., et al., MyoD directly up-regulates premyogenic mesoderm factors during induction of skeletal myogenesis in stem cells. J Biol Chem, 2011. 286(4): p. 2517-25.

96. von Scheven, G., et al., Protein and genomic organisation of vertebrate MyoR and Capsulin genes and their expression during avian development. Gene Expr Patterns, 2006. 6(4): p. 383393.

97. Bothe, I., et al., Dynamic control of head mesoderm patterning. Development, 2011. 138(13): p. 2807-2821.

98. Uehara, M., et al., CYP26A1 and CYP26C1 cooperatively regulate anterior-posterior patterning of the developing brain and the production of migratory cranial neural crest cells in the mouse. Dev Biol, 2007. 302(2): p. 399-411.

99. Roberts, C., et al., Cyp26 genes $a 1, b 1$ and $c 1$ are down-regulated in Tbx1 null mice and inhibition of Cyp26 enzyme function produces a phenocopy of DiGeorge Syndrome in the chick. Hum Mol Genet, 2006. 15(23): p. 3394-410. 
100. Kioussi, C., et al., Identification of a Wnt/Dvl/beta-Catenin --> Pitx2 pathway mediating celltype-specific proliferation during development. Cell, 2002. 111(5): p. 673-685.

101. Diehl, A.G., et al., Extraocular muscle morphogenesis and gene expression are regulated by Pitx2 gene dose. Invest Ophthalmol Vis Sci, 2006. 47(5): p. 1785-1793.

102. Zacharias, A.L., et al., Pitx2 is an upstream activator of extraocular myogenesis and survival. Dev Biol, 2011. 349(2): p. 395-405.

103. Shih, H.P., M.K. Gross, and C. Kioussi, Cranial muscle defects of Pitx2 mutants result from specification defects in the first branchial arch. Proc Natl Acad Sci U S A, 2007. in press.

104. Liu, W., et al., Genetic dissection of Pitx2 in craniofacial development uncovers new functions in branchial arch morphogenesis, late aspects of tooth morphogenesis and cell migration. Development, 2003. 130(25): p. 6375-6385.

105. Lu, J.R., et al., Control of facial muscle development by MyoR and capsulin. Science, 2002. 298(5602): p. 2378-2381.

106. Moncaut, N., et al., Musculin and TCF21 coordinate the maintenance of myogenic regulatory factor expression levels during mouse craniofacial development. Development, 2012. 139(5): p. 958-67.

107. Jackson, A., et al., Endoderm-specific deletion of Tbx1 reveals an FGF-independent role for Tbx1 in pharyngeal apparatus morphogenesis. Dev Dyn, 2014. 243(9): p. 1143-51.

108. Dastjerdi, A., et al., Tbx1 regulation of myogenic differentiation in the limb and cranial mesoderm. Dev Dyn, 2007. 236(2): p. 353-63.

109. Kelly, R.G., L.A. Jerome-Majewska, and V.E. Papaioannou, The del22q11.2 candidate gene Tbx1 regulates branchiomeric myogenesis. Hum Mol Genet, 2004. 13(22): p. 2829-2840.

110. Nowotschin, S., et al., Tbx1 affects asymmetric cardiac morphogenesis by regulating Pitx 2 in the secondary heart field. Development, 2006. 133(8): p. 1565-73.

111. Harel, I., et al., Pharyngeal mesoderm regulatory network controls cardiac and head muscle morphogenesis. Proc Natl Acad Sci U S A, 2012. 109(46): p. 18839-44.

112. Sambasivan, R., et al., Distinct regulatory cascades govern extraocular and pharyngeal arch muscle progenitor cell fates. Dev Cell, 2009. 16(6): p. 810-821.

113. Castellanos, R., et al., Mammalian TBX1 preferentially binds and regulates downstream targets via a tandem T-site repeat. PLoS One, 2014. 9(5): p. e95151.

114. Waldo, K.L., et al., Conotruncal myocardium arises from a secondary heart field. Development, 2001. 128(16): p. 3179-88.

115. Gormley, J.P. and N.M. Nascone-Yoder, Left and right contributions to the Xenopus heart: implications for asymmetric morphogenesis. Dev Genes Evol, 2003. 213(8): p. 390-8.

116. Meilhac, S.M., et al., The clonal origin of myocardial cells in different regions of the embryonic mouse heart. Dev Cell, 2004. 6(5): p. 685-698.

117. Lescroart, F., et al., Clonal analysis reveals common lineage relationships between head muscles and second heart field derivatives in the mouse embryo. Development, 2010. 137(19): p. 3269-79.

118. Camp, E., S. Dietrich, and A. Munsterberg, Fate mapping identifies the origin of SHF/AHF progenitors in the chick primitive streak. PLoS One, 2012. 7(12): p. e51948.

119. Diogo, R., et al., A new heart for a new head in vertebrate cardiopharyngeal evolution. Nature, 2015. 520(7548): p. 466-73.

120. Tirosh-Finkel, L., et al., Mesoderm progenitor cells of common origin contribute to the head musculature and the cardiac outflow tract. Development, 2006. 133(10): p. 1943-1953.

121. Holland, N.D., et al., AmphiNk2-tin, an amphioxus homeobox gene expressed in myocardial progenitors: insights into evolution of the vertebrate heart. Dev Biol, 2003. 255(1): p. 128-37.

122. Xavier-Neto, J., et al., An unauthorized biography of the second heart field and a pioneer/scaffold model for cardiac development. Curr Top Dev Biol, 2012. 100: p. 67-105. 
123. Kitamura, K., et al., Mouse Pitx2 deficiency leads to anomalies of the ventral body wall, heart, extra- and periocular mesoderm and right pulmonary isomerism. Development, 1999. 126(24): p. 5749-5758.

124. Vitelli, F., et al., Tbx1 mutation causes multiple cardiovascular defects and disrupts neural crest and cranial nerve migratory pathways. Hum Mol Genet, 2002. 11(8): p. 915-922.

125. Hu, T., et al., Tbx1 regulates fibroblast growth factors in the anterior heart field through a reinforcing autoregulatory loop involving forkhead transcription factors. Development, 2004. 131(21): p. 5491-5502.

126. Ai, D., et al., Pitx2 regulates cardiac left-right asymmetry by patterning second cardiac lineagederived myocardium. Dev Biol, 2006. 296(2): p. 437-49.

127. Hami, D., et al., Zebrafish cardiac development requires a conserved secondary heart field. Development, 2011. 138(11): p. 2389-98.

128. Wang, W., et al., NK4 antagonizes Tbx1/10 to promote cardiac versus pharyngeal muscle fate in the ascidian second heart field. PLoS Biol, 2013. 11(12): p. e1001725.

129. Stolfi, A., et al., Early chordate origins of the vertebrate second heart field. Science, 2010. 329(5991): p. 565-8.

130. Erwin, D.H., et al., The Cambrian conundrum: early divergence and later ecological success in the early history of animals. Science, 2011. 334(6059): p. 1091-7.

131. Han, J., et al., Meiofaunal deuterostomes from the basal Cambrian of Shaanxi (China). Nature, 2017. 542(7640): p. 228-231.

132. Shu, D.G., et al., Head and backbone of the Early Cambrian vertebrate Haikouichthys. Nature, 2003. 421(6922): p. 526-9.

133. Mahadevan, N.R., A.C. Horton, and J.J. Gibson-Brown, Developmental expression of the amphioxus Tbx1/ 10 gene illuminates the evolution of vertebrate branchial arches and sclerotome. Dev Genes Evol, 2004. 214(11): p. 559-66.

134. Kozmik, Z., et al., Characterization of Amphioxus AmphiVent, an evolutionarily conserved marker for chordate ventral mesoderm. Genesis, 2001. 29(4): p. 172-9.

135. Kusakabe, R., et al., Differential expression of actin genes during amphioxus development. Molecular Biology of the Cell, 1996. 7: p. 706-706.

136. Bone, Q., The central nervous system in amphioxus. J. Comp. Neurol. , 1960. 115(1): p. 27-64.

137. Dufour, H.D., et al., Precraniate origin of cranial motoneurons. Proc Natl Acad Sci U S A, 2006. 103(23): p. 8727-32.

138. Lu, J., J.A. Richardson, and E.N. Olson, Capsulin: a novel bHLH transcription factor expressed in epicardial progenitors and mesenchyme of visceral organs. Mech Dev, 1998. 73(1): p. 23-32.

139. Negroni, E., et al., Cellular Therapies for Muscular Dystrophies: Frustrations and Clinical Successes. Hum Gene Ther, 2016. 27(2): p. 117-26.

140. Yamakawa, H. and M. leda, Strategies for heart regeneration: approaches ranging from induced pluripotent stem cells to direct cardiac reprogramming. Int Heart J, 2015. 56(1): p. 15.

141. Garbern, J.C. and R.T. Lee, Cardiac stem cell therapy and the promise of heart regeneration. Cell Stem Cell, 2013. 12(6): p. 689-98.

142. Daughters, R.S., S.A. Keirstead, and J.M. Slack, Transformation of jaw muscle satellite cells to cardiomyocytes. Differentiation, 2017. 93: p. 58-65.

143. Afshar Bakooshli, M. and P.M. Gilbert, Muscling in on the third dimension. Elife, 2015. 4: p. e06430.

144. Fonoudi, H., et al., ISL1 protein transduction promotes cardiomyocyte differentiation from human embryonic stem cells. PLoS One, 2013. 8(1): p. e55577.

145. Mi, H., et al., PANTHER version 11: expanded annotation data from Gene Ontology and Reactome pathways, and data analysis tool enhancements. Nucleic Acids Res, 2017. 45(D1): p. D183-D189. 
Figure 1: Origin of head muscles, muscle connective tissue and head muscle innervation; plotted onto a three day old chicken embryo.

(A) The pre- and para-otic, unsegmented paraxial head mesoderm, with a contribution by the prechordal plate, provides the extraocular (orange) and the rostral pharyngeal arch muscle precursors (pink). The five occipital somites together with the caudally adjacent cervical somites (green) provide the neck muscles associated with the neck vertebral column. Moreover, the occipital somites provide the hypoglossal/ hypopharyngeal muscles ( $\mathrm{hg} / \mathrm{hp}$ ). The lateral head mesoderm provides the primitive, tubular heart (lilac). The occipital lateral mesoderm has been suggested as source for the neck muscles that link the skull and the shoulder (asterisk). The origin of the muscle in the caudal pharyngeal arches is not fully clear. Since the paraxial head mesoderm that generates the pharyngeal arch muscles delivers the in- and outflow tract of the mature heart, and because the expression of paraxial and lateral head mesoderm markers overlaps, the boundary between the two tissues is ill-defined. This area, also termed cardiopharyngeal field, is marked by pink-lilac stripes.

(B) The connective tissue and tendons of extraocular muscles, the muscles of the rostral pharyngeal arches, the hypoglossal/hypobranchial muscles and the muscles linking the head and the shoulder is a derivative of cranial neural crest cells. In the trunk, connective tissues originate from mesoderm.

(C) The extraocular muscles, the hypopharyngeal muscles and all muscles in the trunk are innervated by somatic motor neurones.

(D) The metameric pharyngeal muscles are innervated by special visceral motor neurones. The nonsomitic neck muscles are innervated by the accessory nerve (nerve XI, not shown), with a contribution from the cervical nerves.

Abbreviations: eom, extraocular muscles; hg/hp, hypoglossal/ hypopharyngeal muscles; pam, pharyngeal muscles; cranial nerves: III, oculomotor nerve; IV, trochlear nerve; V, trigeminal nerve; VI, abducens nerve; VII, facial nerve; IX, glossopharyngeal nerve; $\mathrm{X}$, vagal nerve; XII, hypoglossal nerve.

Figure 2. Expression patterns of $(A, B)$ Tbx1 mRNA, (C,D) Myf5 mRNA, (E,F) sarcomeric myosin protein and $(\mathrm{G}, \mathrm{H})$ Pax7 mRNA in 2.5 day $(\mathrm{A}, \mathrm{C}, \mathrm{E}, \mathrm{G})$ and $3.5-4$ day $(\mathrm{B}, \mathrm{D}, \mathrm{F}, \mathrm{H})$ old chicken embryos. Tbx1 is expressed in the progenitors of the lateral rectus extraocular muscle, the progenitors of the developing pharyngeal arch muscles and the occipital lateral mesoderm that provides the cucullaris muscle linking the skull and the shoulder (asterisk). The gene is also expressed in the pharyngeal endoderm and along the caudal border of the $2^{\text {nd }}$ pharyngeal arch (open arrowhead). Head mesoderm-derived muscle anlagen express Myf5 (indicating the commitment to myogenesis) and sarcomeric myosin (marking terminal differentiation) significantly later than somites. In extraocular and pharyngeal arch muscles, expression of the muscle stem cell marker Pax7 emerges after the onset of differentiation. In the somite and for hypoglossal/hypopharyngeal muscles, Pax7 expression precedes that of Myf5 and sarcomeric myosin.

Abbreviations: do, dorsal oblique muscle; dr, dorsal rectus muscle; hg/hp, hypoglossal/ hypopharyngeal muscles; ht, heart; hy, hyoid arch (2 $2^{\text {nd }}$ arch) muscles; Ir, lateral rectus muscle; ma, mandibular arch ( $1^{\text {st }}$ arch) muscles; mr, medial rectus muscle; ncc, neural crest cells; pam, pharyngeal arch muscles; s, somite; vo, ventral oblique muscle; vr, ventral rectus muscle. 
Figure 3. Markers for the early paraxial and lateral head mesoderm.

(A) Schematic representation of a chicken embryo after 1 of its 21 days of development, rostral to the top. Anatomical landmarks are annotated; the somite about to form is marked by an arrowhead. The paraxial head mesoderm is located underneath the rostral neural plate, neighbouring the axial mesoderm (pre-chordal plate and notochord).The lateral head mesoderm is located lateral to the paraxial head mesoderm.

(B-F) mRNA expression patterns of the genes indicated on top of the panel. Cyp26C expression labels the entire paraxial head mesoderm, its expression fading towards the developing $1^{\text {st }}$ somite. Pitx 2 marks the rostral head mesoderm, Tbx1 the caudal head mesoderm and underlying endoderm, Nkx2.5 the prospective heart cells developing from the lateral head mesoderm. The developing pair of somites expresses Paraxis ( $F$, blue staining), the notochordal cells emerging from Hensen's node express Chordin ( $F$, red staining).

Abbreviations: end, endoderm; hn, Hensen's node; Ihm, lateral head mesoderm; not, notochord; np, neural plate; phm, paraxial head mesoderm; ps, primitive streak.

Figure 4. The key differences between (A) the head and (B) the trunk programmes of vertebrate myogenesis.

(A) The early head mesoderm genes Pitx2, Msc (and Tcf21/Capsulin) and Tbx1 set up the head mesoderm as a heart-skeletal muscle competent tissue. Onset of Myf5 and then MyoD expression commits cell to the skeletal muscle lineage. It also allows the formation of muscle stem cells which may retain some of the early, head mesodermal properties. Head myogenesis is inhibited by Wnt signalling.

(B) The somite is a muscle-, but not heart-competent tissue. In amniotes, the early somite expresses Pax 3 and Pax7 before the Mrf genes, and cells with continued Pax7 expression become muscle stem cells. Wnt and Shh signalling drives cells into muscle differentiation. Dotted line: cells with a temporary phase of Mrf expression may still be able to become muscle stem cells.

Figure 5. Gene Ontology enrichment.

Lists were generated using all transcripts differentially expressed (with a $\mathrm{p}$-adjusted value less than 0.05 ) between paraxial head mesoderm ( $\mathrm{phm}$ ) and segmental plate (sp, pre-somitic) mesoderm of 16 somite stage chicken embryos. Differentially expressed transcripts were separated into two lists based on their expression levels between PHM and SP. GO term statistical over-representation analysis was performed for each list using PANTHER-GO classification system using the Slim-GO molecular function data set [145]. The percentage of transcripts for the experiment (blue) was calculated by dividing the number of transcripts annotated with the particular GO term found in the total number of transcripts of the PHM and SP biopsies by the total number of annotated transcripts in the chicken genome (GrCh38). For comparison (purple), the total number of transcripts annotated with the specific $\mathrm{GO}$ term was divided by the total number of annotated transcripts in the chicken genome. For both PHM and SP, GO terms are sorted by fold enrichment. 
Figure 6. Fate of the vertebrate paraxial and lateral head mesoderm.

(A) Schematic representation of a chicken embryo after 1 day of development as shown in Fig.3, rostral to the top. (B) Schematic cross section of the embryo depicted in (A), dorsal to the top. The paraxial head mesoderm is shown in turquoise, the lateral head mesoderm in pink, the area where phm and Ihm marker gene expression overlaps is shown as striped.

Anatomical landmarks are annotated; the somite about to form is marked by an asterisk in (A). Abbreviations: conn. tissue; connective tissue; ect, surface ectoderm; end, endoderm; hn, Hensen's node; Ihm, lateral head mesoderm; ncc, neural crest cells; nf, neural folds; not, notochord; np, neural plate; nt, neural tube; phm, paraxial head mesoderm; ps, primitive streak.

Note that the Ihm delivers the primitive heart and the cranial equivalent of the body wall, the pericardial cavity. The phm delivers head skeletal muscle, some cartilage and bone, and the cardiac cells that are secondarily added on to the heart. 


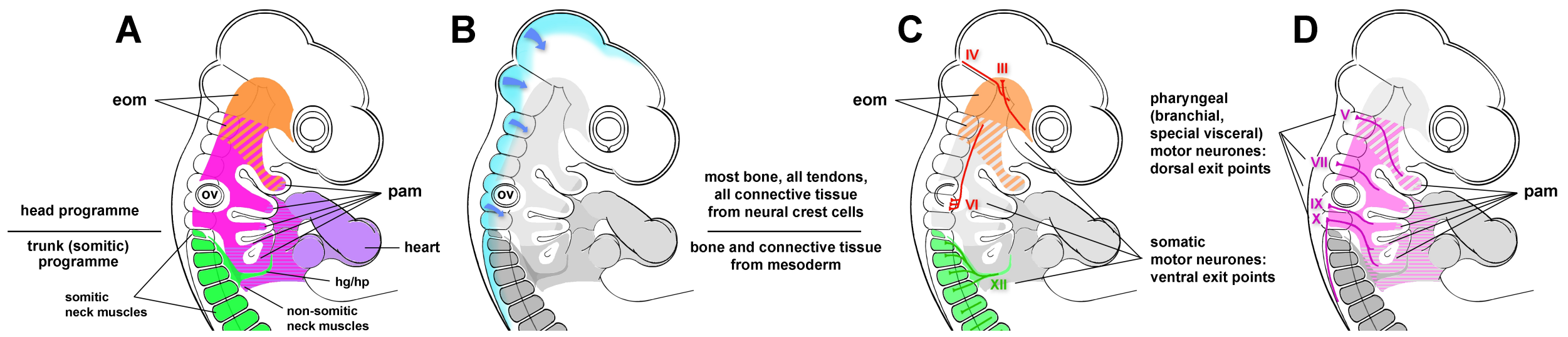


Tbx1

A

B

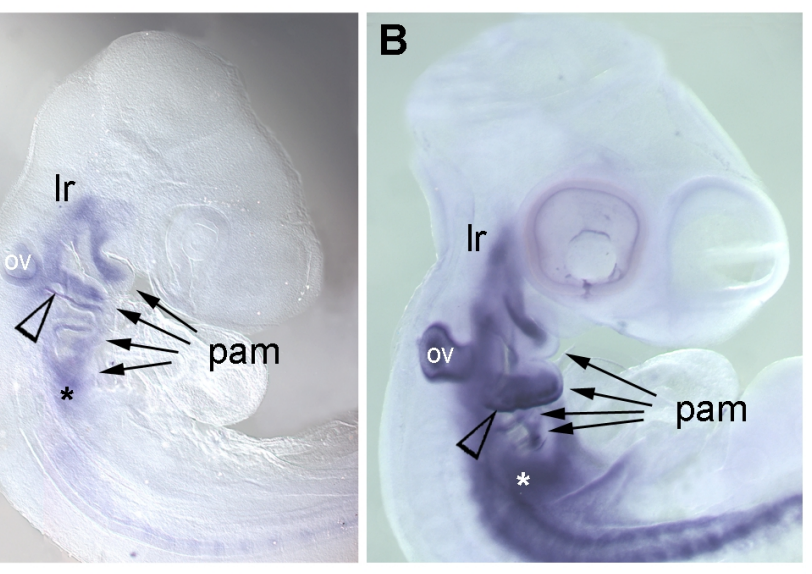

Myf5

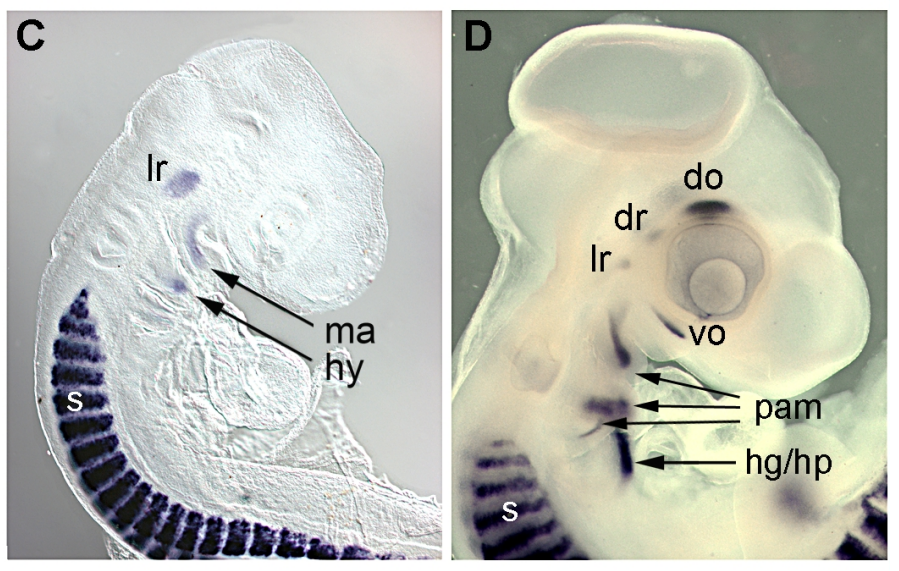

sarcomeric Myosin

E

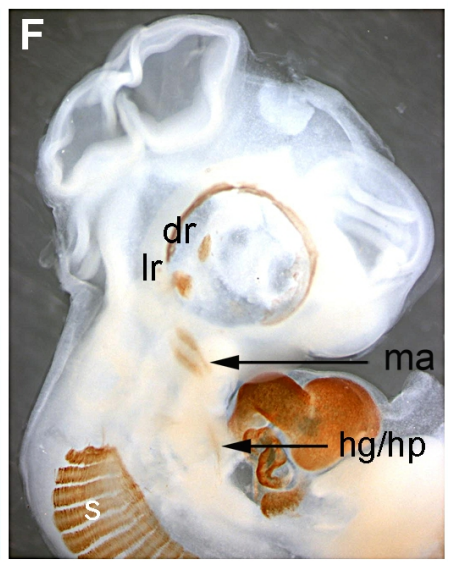

Pax7

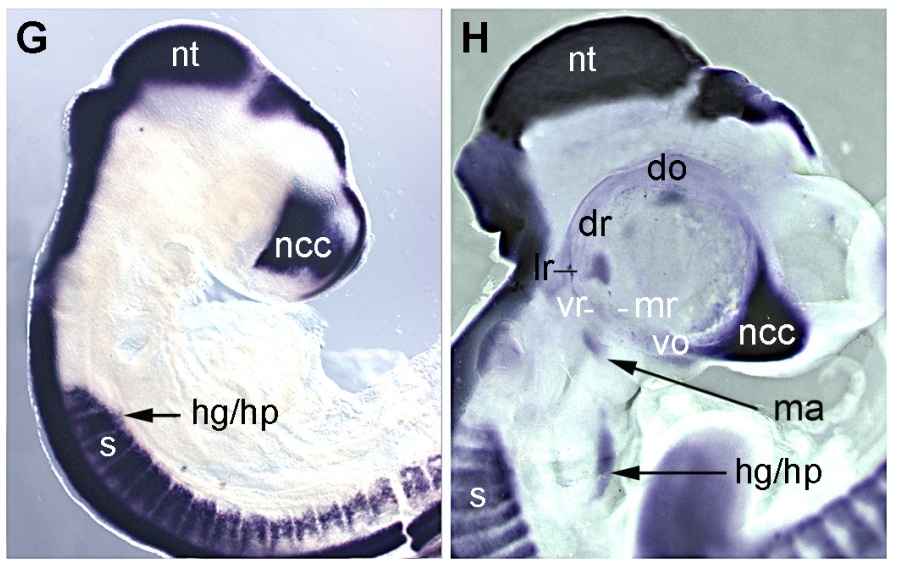


schematic:

\section{Cyp26C1}

Pitx2

Tbx1

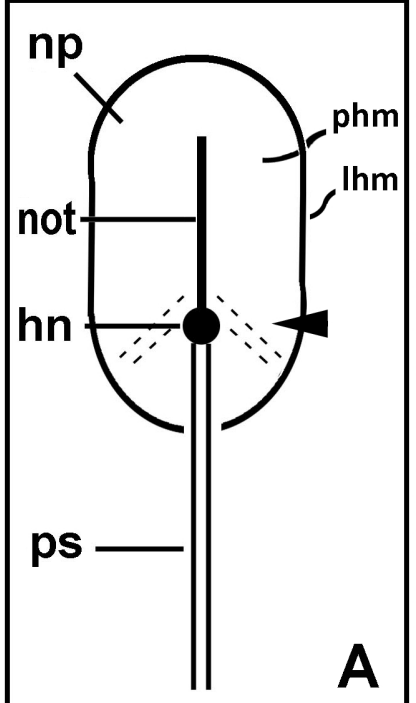

B

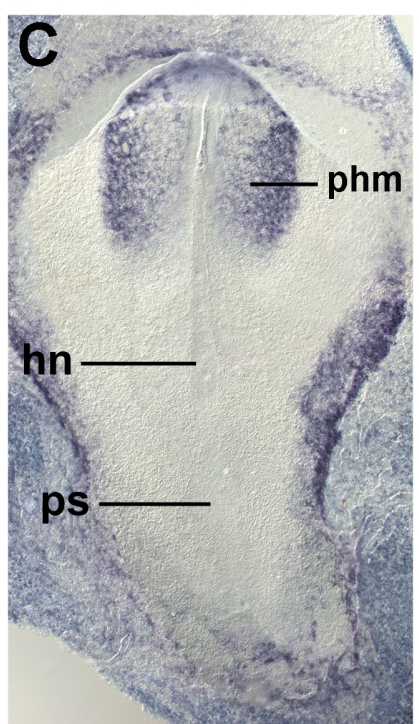

D

ps

A

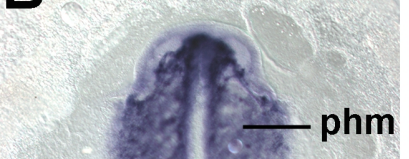

nn

ps
Nkx2.5

E

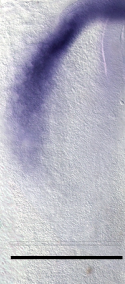

- Ihm

ps

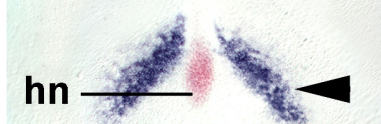

ps

Paraxis + Chordin F

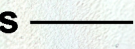




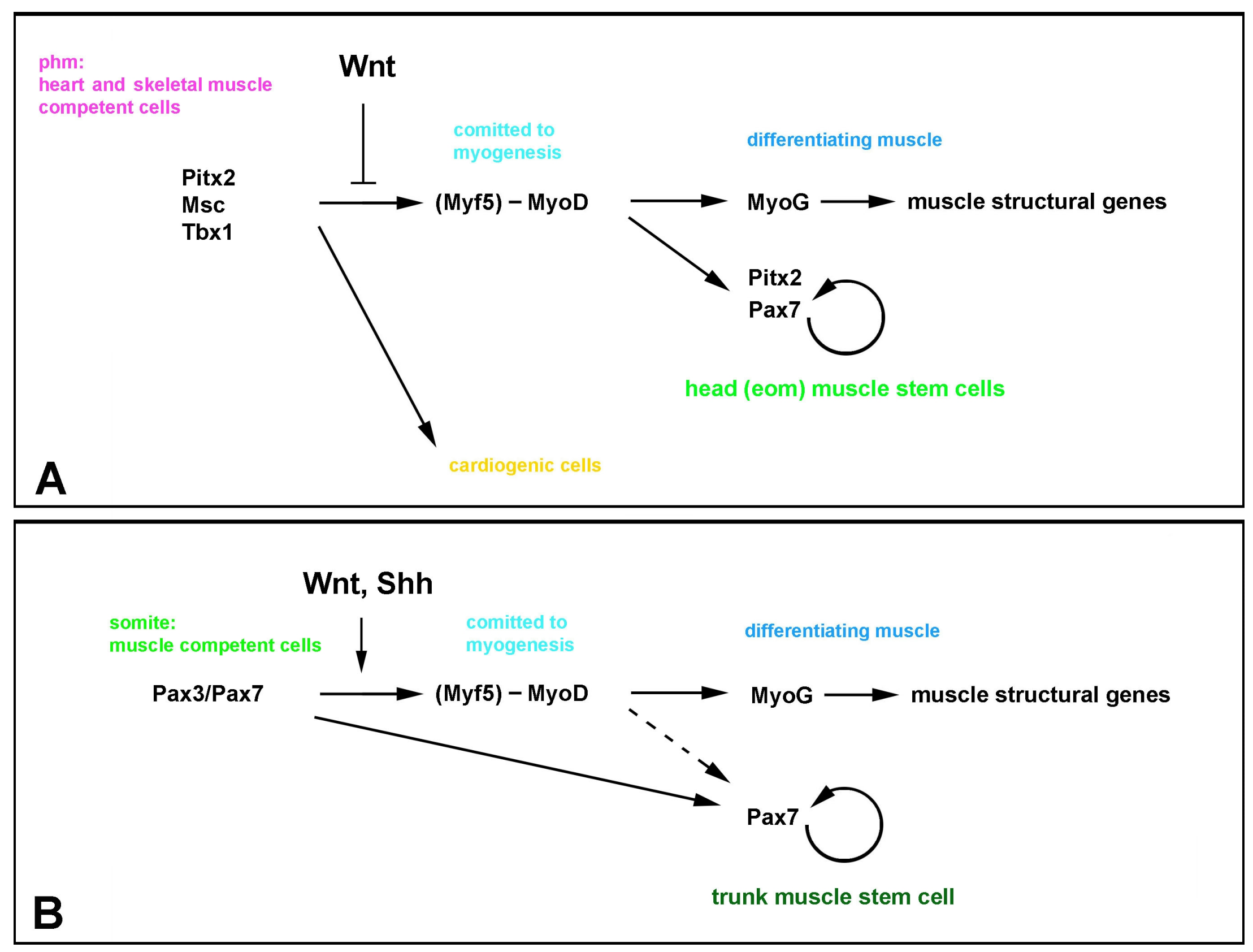




\section{GO term}

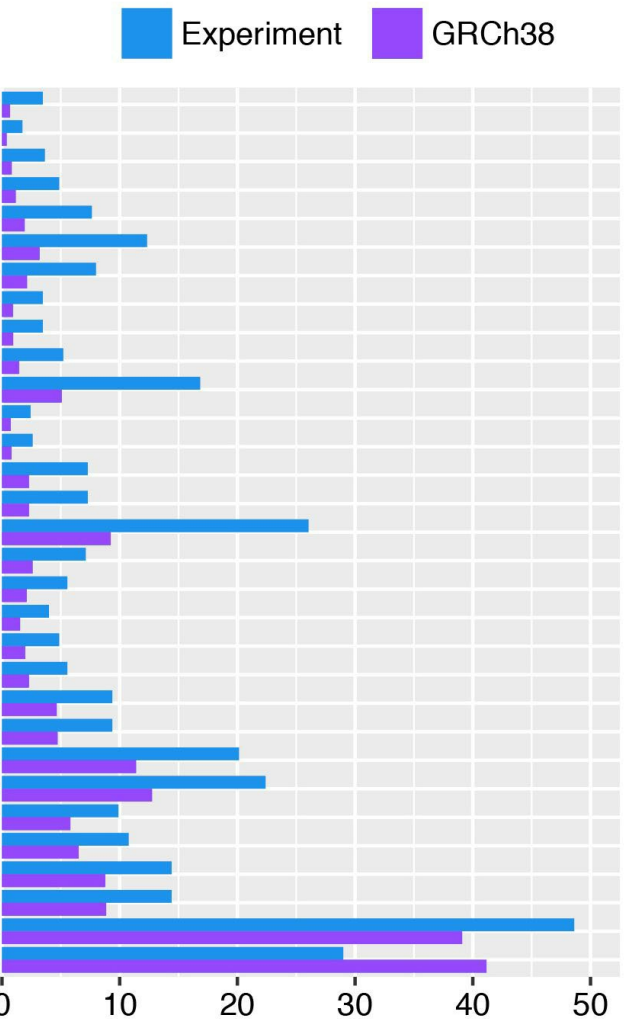

transcription from RNA polymerase II promoter -

heart development anatomical structure morphogenesis muscle organ development ectoderm development nervous system development mesoderm development skeletal system development transmembrane receptor protein tyrosine kinase signaling -
cell-cell adhesion system development pattern specification process biological adhesion cell adhesion developmental process cellular component morphogenesis cell differentiation -

synaptic transmission cellular component movement

regulation of transcription from RNA polymerase II promoter intracellular signal transduction signal transduction cell communication single-multicellular organism process multicellular organismal process cellular process -

digestive tract mesoderm development pattern specification process female gamete generation segment specification angiogenesis -

skeletal system development muscle organ development embryo development spermatogenesis mesoderm development ectoderm development nervous system development anatomical structure morphogenesis gamete generation system development regulation of transcription from RNA polymerase II promoter developmental process reproduction transcription from RNA polymerase II promoter transcription, DNA-dependent RNA metabolic process signal transduction cell communication Unclassified -

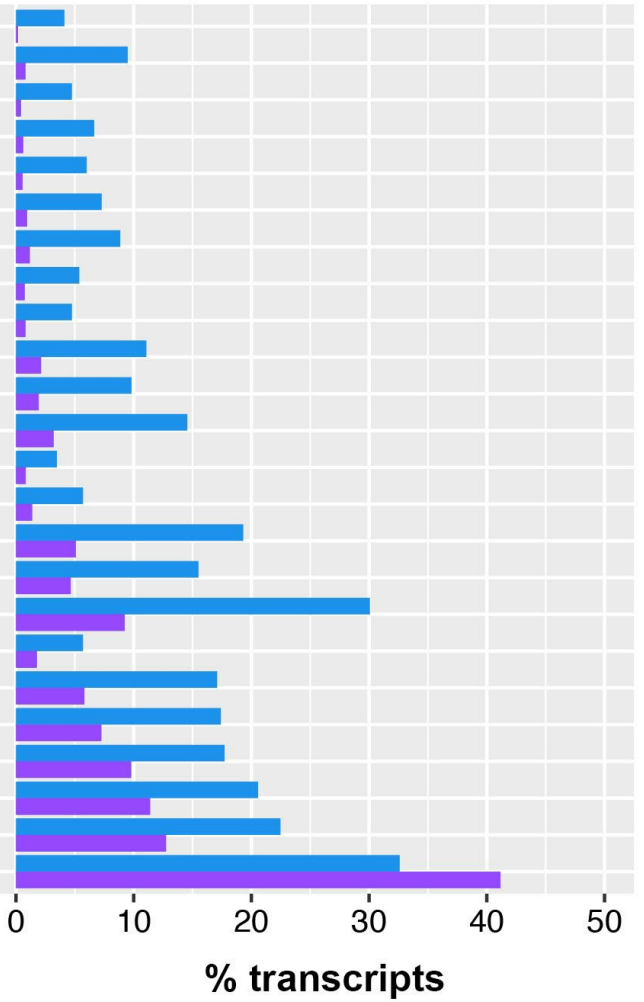




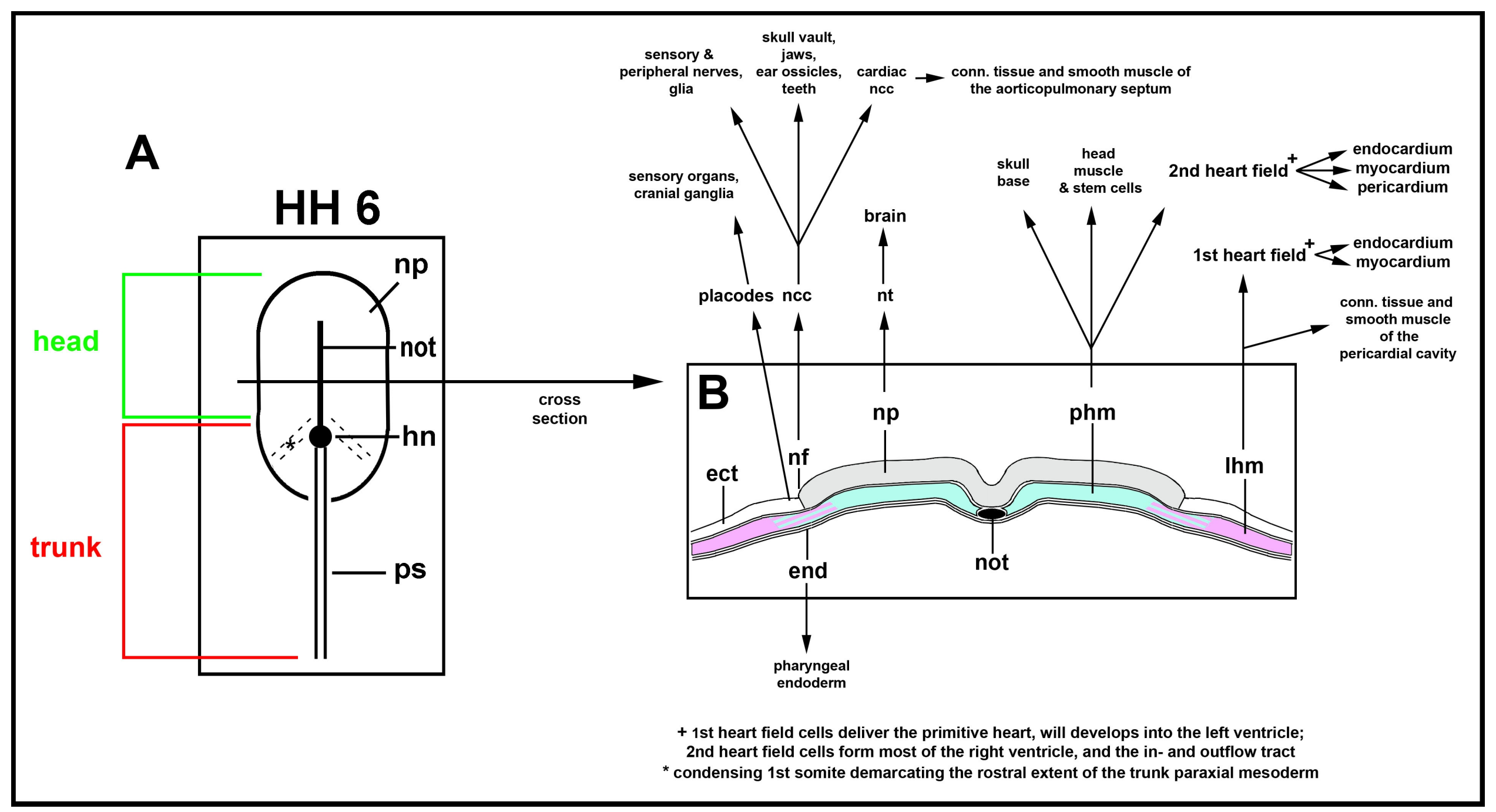


Box: Specialist terms at a glance

\begin{tabular}{|c|c|}
\hline Term & Explanatory text \\
\hline \multicolumn{2}{|r|}{ Mesodermal cells and their fate } \\
\hline Primary heart field & all the mesoderm that delivers the primitive heart of the embryo \\
\hline Secondary heart field & $\begin{array}{l}\text { all the mesoderm that is added on to the primitive heart and is } \\
\text { required to form the mature heart }\end{array}$ \\
\hline Anterior heart field & $\begin{array}{l}\text { anteriorly/rostrally located part of the secondary heart field, } \\
\text { contributes to the outflow tract }\end{array}$ \\
\hline Posterior heart field & $\begin{array}{l}\text { posteriorly/caudally located part of the secondary heart field, } \\
\text { contributes to the inflow tract }\end{array}$ \\
\hline $\begin{array}{l}\text { Cardio-pharyngeal field, } \\
\text { cardio-pharyngeal } \\
\text { mesoderm }\end{array}$ & $\begin{array}{l}\text { area of mesoderm that contributes both to the pharyngeal skeletal } \\
\text { musculature and to the heart }\end{array}$ \\
\hline \multicolumn{2}{|r|}{ Mesoderm defined by its initial position } \\
\hline Axial mesoderm & $\begin{array}{l}\text { notochord, mesoderm running along the longitudinal axis of the } \\
\text { embryo }\end{array}$ \\
\hline Pre-chordal mesoderm & mesoderm at the rostral end of the notochord \\
\hline Paraxial mesoderm & $\begin{array}{l}\text { mesoderm laterally adjacent to the notochord and initially } \\
\text { underneath the neural plate }\end{array}$ \\
\hline Lateral mesoderm & $\begin{array}{l}\text { mesoderm lateral to the paraxial mesoderm. The lateral mesoderm } \\
\text { splits into two layers, thereby forming the coelom (trunk) or } \\
\text { pericardial cavity (head); in the trunk, paraxial and lateral mesoderm } \\
\text { are separated by the intermediate mesoderm which forms the } \\
\text { urogenital system. }\end{array}$ \\
\hline $\begin{array}{l}\text { Somatic lateral } \\
\text { mesoderm= somatopleura }\end{array}$ & $\begin{array}{l}\text { superficial leaf of the lateral mesoderm, associated with the } \\
\text { ectoderm }\end{array}$ \\
\hline $\begin{array}{l}\text { Splanchnic lateral } \\
\text { mesoderm = } \\
\text { splanchnopleura }\end{array}$ & internal leaf of the lateral mesoderm, associated with the endoderm \\
\hline Paraxial head mesoderm & unsegmented paraxial mesoderm rostral to the series of somites \\
\hline Trunk paraxial mesoderm & paraxial mesoderm destined to form somites \\
\hline Somites & segmented trunk paraxial mesoderm \\
\hline Occipital somites & $\begin{array}{l}\text { rostral-most somites in the somitic series, were secondarily } \\
\text { incorporated into the head during vertebrate evolution }\end{array}$ \\
\hline \multicolumn{2}{|r|}{ Head skeletal muscle } \\
\hline Genuine head muscles & $\begin{array}{l}\text { skeletal muscle arising from the non-somitic paraxial head } \\
\text { mesoderm, likely with a contribution form the occipital lateral } \\
\text { mesoderm }\end{array}$ \\
\hline $\begin{array}{l}\text { Somite-derived head } \\
\text { muscles }\end{array}$ & skeletal head muscle arising from somitic cells \\
\hline Extraocular muscles & muscles moving the eye ball \\
\hline $\begin{array}{l}\text { Pharyngeal arch muscles, } \\
\text { branchial arch muscles, } \\
\text { branchiomeric muscles }\end{array}$ & $\begin{array}{l}\text { muscles developing from the mesodermal core of the metameric } \\
\text { pharyngeal arches }\end{array}$ \\
\hline \multicolumn{2}{|r|}{ Chordate pharyngeal apparatus } \\
\hline Pharyngeal arches & $\begin{array}{l}\text { reiterated swellings on either side of the pharynx, separated by } \\
\text { pouches or slits, initially used for filter feeding, later also for } \\
\text { respiration (hence the alternative terms branchial or gill arches) }\end{array}$ \\
\hline
\end{tabular}

